MedieKultur | Journal of media and communication research | ISSN 1901-9726

Article - Theme section

\title{
Research method for locative games
}

\author{
Luiz Adolfo Andrade
}

MedieKultur 2018, 64, 52-70

Published by SMID | Society of Media researchers In Denmark | www.smid.dk

The online version of this text can be found open access at https://tidsskrift.dk/mediekultur

\begin{abstract}
This paper presents a methodology approach for locative game studies using actornetwork theory (ANT) as a basis. The hypothesis proposes that the ANT could be useful because it focuses on agencies between humans and non-humans, while it provides useful categories to support the researcher in the description of an emerging phenomenon. Locative gaming offers a rich and informative experience for which the concepts of ANT can be successfully applied because it connects many human and non-human actants. In the attempt to develop a research method for locative games which uses the actor-network theory, this study provides a description and evaluation of a number of game sessions of Pokémon GO played in Copenhagen during the summer of 2017.
\end{abstract}

\section{Initial thoughts}

Since game studies emerged as a multidisciplinary field of research in the late 1990s, it has become possible to respond effectively to the demands for effective methodologies. For example, Lankoski and Björk (2015), in what was perhaps one of the first comprehensive texts on the subject to be published, sought to provide an overview of proposals 
on research methods in game studies. Previously, these resources were available only in conference lectures or isolated papers.

However, Lankoski and Björk (2015, p. 6) confess that their book fails to cover all the possibilities which might exist regarding quantitative, qualitative, and mixed methods for game studies. One of these gaps is in actor-network theory (ANT), a branch of the social sciences which focuses on the agencies between humans and non-humans; ANT researchers should examine how these actors act, treating them equally.

For Bienia (2016), an ANT study does not take known elements for granted to achieve equality, but examines empirically how these elements act in everyday experiences, e.g., a game session under the lens of actor-network theory. The focus of the study moves from preselected concepts toward processes which depend on collaboration and negotiation. Nevertheless, Bienia and others (Giddens, 2006; Cypher \& Richardsson, 2006; Chen, 2010; Jensen \& Jensen, 2014; Hung, 2017) fail in a core aspect: Their approaches lack the importance of controversy in a description using ANT; a controversy has a meaningful function in ANT because it reveals situations where the actors disagree. Ultimately, I agree that a controversy cannot replace a research question or hypothesis; it highlights a productive moment to the researcher who then starts a description using ANT.

This paper presents a methodology approach for locative games studies, using as a reference various concepts of ANT, i.e., mediator, controversy, translation, and others. The hypothesis proposes that ANT could be serviceable to explore locative gaming because it focuses on agencies between humans (the player, pedestrians, etc.) and non-humans (smartphones, wristbands, rules, game mechanics, the space, everyday objects, etc.). In the same way, ANT provides useful categories to support the researcher in the attempt to describe an emerging phenomenon, as in the case of locative gaming.

Locative games use the geographical space as the setting for players' interaction or agencies; to achieve this goal, the game designer should embed locative media in the game settings. My choice, then, was to describe data I collected in game sessions of Pokémon GO, which took place in Copenhagen during the summer of 2017. However, my intention here is to provide a reflection regarding the efficacy of concepts from ANT in locative game research, not present a case study about Pokémon GO.

This work is divided into two levels. First, I present a literature review by discussing the concept of locative game, using a space-based perspective. Second, I exhibit a number of approaches to methodologies for game studies, followed by a discussion regarding concepts from ANT, including mediator, intermediary, translation, delegation, inscription, and controversy. My choice is to focus on Latour's thoughts because they support the importance of controversies in a description using ANT; also, Latour provides a didactic overview regarding ANT's core concepts. Finally, I describe situations during the time I spent playing Pokémon GO, in an attempt to propose a research method for locative games using ANT. 


\section{Defining locative games}

Locative games use space as the basis for players' interactions. It embodies locative media's functions into its settings, using location-based technologies (GPS, wireless networks, smartphones, etc.) and location-based services (maps, geotags, augmented reality browsers, etc.) as resources for the game's design. The term locative media was originally proposed by Kalnins (2003) as the title for a workshop hosted by RIXC in 2003, an electronic art and media center in Latvia. Kalnins' purpose was to label the creative use and appropriation of location-based technologies and location-based services.

To Brazilian theorist Lemos (2010, p. 10), "place and context are essential in the communication process involving locative media. The information flow runs locally promoting new uses of space." Locative media is one way to add digital content to locations in the geographical space. In these cases, as a rule, transmission and reception must always occur at the local level, providing services according to the user's position.

Space is a broad term which could be used in many contexts. For instance, geographical space refers to location specifics; it takes the forefront in the communication process involving locative media, pointing to ideas such as the "spatial turn in media studies" (Jansson \& Falkheimer, 2006). On the other hand, the notion of space could be related to practices, simulation, and representation, pointing to a discussion on issues regarding the "social space or the production of perceived, conceived and lived spaces" (Lefebvre, 1991) and "the reassertion of the space in social sciences" (Soja, 1989).

In game studies, Aarseth considers space as an important parameter for computer game analysis, suggesting the relevance of a spatial perspective.

The defining element in computer games is spatiality. Computer games are essentially concerned with spatial representation and negotiation, and therefore a classification of computer games can be based on how they represent - or, perhaps, implement - space (Aarseth, 2000, p. 154).

Setting a space-based perspective in game studies, we can classify computer games into two main genres. First, we have the video games, in which the geographical space is a kind of background for players' interactions, but it is as a residual component with less importance than the game experience itself. In video games, the players can choose any space to play or change it randomly, whenever something disrupts their attention. Second, we have the locative games, in which the geographical space is the support for players' interactions, taking the forefront in the process. The portion of space used to play the game should remain the same until the end of the session, and, if the player decides to restart the game using another space, he or she will lose all the progress acquired in the match.

Flanagan (2009) understands that locative games offer an ambiguous ambient game experience because the players explore both participation and space by combining physical and technological play. It is important to highlight that, during the first decade of this century, there was an explosion of terminology in an attempt to label these projects, such 
as alternate reality game (ARG) (Szulborsky, 2005; McGonigal, 2007; Andrade, 2012), pervasive game (Montola et al., 2009), augmented reality game (AR game) (Tan \& Soh, 2010), mixed-reality game (Benford et al., 2006; Hinske et al., 2007) mobile and urban games (Mayra, 2012), and others.

Ultimately, all these different terms do not describe disconnected traditions; they are all attempts at grasping the same emerging phenomenon. To Bienia (2016), these concepts reconstruct a dichotomy of digital and real elements because the dichotomy is the starting point to mix, pervade, or hybridize these elements in the process of gaming.

However, the label locative game seems to me more appropriate because it focuses on the mandatory use of location-based technologies and location-based services in game settings. At the same time, the improvement of mobile operating systems, such as iOS (2008) and Android, (2008), and the rise of mobile stores, as in the case of App Store and Android Market, replaced in 2012 by Google Play, helped to establish locative games in the mobile gaming market. Users can download, sometimes for free, all sorts of locative games from these stores, such as Ingress, Code Runner, Ghost Buster: Paranormal Blast, The Landlord, and Pokémon GO.

In this scenario, Pokémon $\mathrm{GO}$ has become as a successful project. According to Forbes Magazine in April 2017, more than 65 million users downloaded the game from App Store and Google Play, and $60 \%$ of these have remained active in the game. The growth of locative gaming and the mobile market attracts the attention of some scholars, and Pokémon Go has been appropriated as an object of study since last year.

Based on its widespread popularity, Colley and others (2017) analyze some geographic effects of locative gaming on a global scale, considering players distributed in five countries. Lucsak-Roesch (2017) focuses on the short- and long-term implications which the proliferation of $A R$ in games may have in disaster-prone regions, especially the city of Wellington in New Zealand. Licoppe (2017) conducts a comparative study considering the use of AR resources in previous games, such as Mogi, in the early 2000s, and Wong (2017) uses Pokémon $\mathrm{GO}$ as a tool to measure the physical activity level of players.

However, there is not a specific methodological approach to comprehensively explore a locative game such as Pokémon GO. In the next section, I will present some proposals for research methodology for game studies, followed by an approach to ANT.

\section{Game studies and research method}

Issues regarding research method for game studies have been common since it emerged as a multidisciplinary field of research in the late 1990s. Game studies have a lack of methodologies for critical analysis, and scholars have begun to address this need, yet they do not systematically lay out the elements of a game which can help a researcher with the specifics of analysis (Consalvo \& Dutton, 2006). Some scholars appropriate existing methodologies from other scientific areas and apply them to game studies, as in the case 
of netnography (Kozinets, 1998) and virtual ethnography (Hine, 2000), which are used in many research projects regarding virtual environments or massively multi-player online role-playing games (MMORPGs). Thus, applying ANT into locative game studies is perhaps a very logical and potentially effective endeavor.

On the other hand, there are certain insights provided by some scholars regarding the analysis of games. Konzack (2002) presents perhaps the first attempt to create a specific method to study computer games, avoiding transfer from other fields to game studies. Konzack's proposal is based on seven specific layers: hardware, program code, functionality, game play, meaning, referentiality, and socio-culture. For this author, each of these layers may be considered individually, but an entire investigation of any computer game must be analyzed from every angle.

Aarseth (2003) considers this proposal useful in at least three different ways: first, in the thorough analysis of a single, specific game (Soul Calibur), down to the last detail; second, as a general, descriptive layered model of games; and third, as a timely reminder of the many-sided, complex media machines which computer games are. On the other hand, Aarseth perceives a weakness and a strength in Konzack's model, which emphasize the same thing: the seven separated layers appear to be equally important. Most games, he says, are very interesting in all these layers, but few present actual innovations in more than one or two of them; so, this methodology is probably best used as an open framework, where the analyst can choose from two to four of the seven layers to work with.

Inspired by Konzack's work, Aarseth presents his proposal for a research method, which points to three ways of acquiring knowledge about any kind of game.

Firstly, we can study the design, rules and mechanics of the game, insofar as these are available to us, e.g. by talking to the developers of the game. Secondly, we can observe others' play, or read their reports and reviews, and hope that their knowledge is representative and their play competent. Thirdly, we can play the game ourselves" (Aarseth, 2003, p. 3).

Following his reflection, Aarseth considers that the third way is clearly the best, especially if combined or reinforced by the other two. If we have not experienced the game personally, he says, we are liable to have severe misunderstandings, even if we study the mechanics and try our best to guess at their workings. For Aarseth, unlike film studies and literature, merely observing the action will not put us in the role of the audience. When others play, what takes place on the screen is only partly representative of what the player experiences. The other, and perhaps more important, part is the mental interpretation and exploration of the rules which, of course, are invisible to the non-player.

Consalvo and Dutton (2006) understand that Aarseth does not present a clear and concrete methodology; he only argues that game researchers must play games and gather as much information about the game as possible from other sources. Starting with this caveat, they propose a kind of methodological toolkit based in four core elements, which is offered as a starting point for researchers interested in studying digital games in order 
to facilitate the research without losing those aspects of games that make them the dynamic artefacts of culture.

Based on the experience of playing The Sims and three of its expansion packs: Livin' Large, House Party, and Hot Date, the four elements prescribed by Consalvo and Dutton are: (i) object inventory, a useful way for researchers to understand that one role objects can play in a game is to create an inventory which catalogues all known objects, which can be found, bought, stolen, or created, and to produce a document listing the various properties of each item; (ii) interface study, an analysis of how players can easily understand on-screen information and how it provides the player with information concerning the life, health, location, or status of the character(s), as well as battle or action menus, nested menus which control options, such as advancement grids or weapon selections, or additional screens which give the player more control over manipulating elements of gameplay; (iii) interaction mapping, a means to examine the choices which the player is offered in regard to interaction not with objects, but with other player characters, and/ or with non-player character (NPC); and (iv), gameplay logging, a way to connect and explore the game world and to understand the emergent aspects of the game; here, the researcher is less interested in the options offered to the player than in what can happen when the player does something the game maker did not intend and with what result.

Considering these approaches in game research, it is possible to list some relevant aspects which could be useful in an attempt to propose a mixed method to locative games using ANT. First, it is important to select one game and try to describe it thoroughly, such as ANT scholars usually do regarding other issues. Here, the researcher can use all sorts of criteria to make this choice: originality, popularity, and technological innovation in gameplay, among others. Second, it is important to consider the role of the objects, which are used by the player to interact during the game experience (physical artefacts like smartphones, and game tokens, such as badges, weapons, etc.). Finally, the researcher must play the game to understand its gameplay, game mechanics, rules, puzzles, and other factors; the activity of "play a game" allows the researcher to understand entities and forces in ANT, such as mediators, agencies, and controversies.

\section{On ANT}

Law (2007, p. 3) points out the rise of ANT in Paris from 1978 to 1982. The term, devised by Callon, appeared around 1982 as a subset of the social theory used to describe their approaches to studies in scientific and technical innovation. Latour (2005) understands approaches in social sciences in two different ways: (i) the traditional, inspired in Durkheim's work, called sociology of the social; (ii) the critical, interested not only in social tiers among people, as is the first one, but also in the associations between human and non-humans. This approach became what is now known as the ANT, or the sociology of associations, or "associology" - to use one of Latour's expressions. 
In this way, ANT does not celebrate the idea that there is a difference between people on one hand and objects on the other; it denies that people are necessarily special, and its focus is on the associations (agencies) between humans and non-humans (devices, rules, laws, machines, subsets, objects, etc.). According to Law,

The actor-network approach is not a theory. Theories usually try to explain why something happens, but actor-network theory is descriptive rather than foundational in explanatory terms, which means that it is a disappointment for those seeking strong accounts. Instead it tells stories about "how" relations assemble or don't [...] it is better understood as a toolkit for telling interesting stories about, and interfering in those relations (2007, p. 3).

This comprehension of ANT as a "toolkit for telling stories" is supported by Latour in his highly regarded work Reassembling the Social: An Introduction to Actor-Network Theory. Latour and others highlight a specific vocabulary in an attempt to provide insights for researchers in the task of defining and describing social experiences, as in the case of locative games.

First, we have the actor or actant ${ }^{2}$, a term derived from the actantial model of semiotics analysis of narratives, which is also used in linguistics, sociology, and other fields, and which, through the lens of ANT, can be human or non-human and refer to anyone or anything that enables or causes others to act (Latour, 2005). Second, the term mediator is used to describe the actant's role in the network. According to Latour (2005, p. 39), a mediator represents the actor in the actor-network. Mediators are entities that do things and make the others do things, transforming, translating, distorting, and modifying the meaning they are supposed to possess. With mediators, the incoming information is different from the outcomes. On the other hand, Latour situates the intermediary, another entity that transports meaning or force without transformation: defining its input is enough to define its output. Intermediaries can be anything that circulates between actors, as well as what helps to define the relations between them.

These relations, or agencies, according to ANT scholars, are commonly described in specific ways. First, there is translation, which consists of the process operated by mediators to transform and send the information to another actant. Latour (1988, p. 108) conceives of translation as "the interpretation given by the fact-builders of their interests and that of the people they enrol." The author presents five forces of interests or translating interests which would be present in all translation agencies: (i) translation one, the simple and basic form, occurs when an actor simply chooses to activate the network; (ii) translation two happens if another actant starts to become stronger than the first one in the network, shifting the researcher's focus; (iii) translation three allows the analyst to change his or her way in the network, finding shortcuts as attempt to reach the objectives; (iv) translation four, related to what Latour calls explicit interest, occurs when actants know more or less what they want, and a list of their goals may, at least, to be set up, either by 
them or by observers; and ( $v$ ) translation five occurs when a force becomes indispensable to reach another movement in the network, i.e., it is mandatory to buy a ticket to take a bus.

The second agency, which I intend to highlight, is delegation, which happens after a translation process. Delegation occurs when a mediator transfers the agency from another network to make an actant do something. It is the same situation as that of Project Waymo, ${ }^{3}$ which started as Google's self-driving car (Lemos, 2013). Waymo is an electric car prototype, which ferries passengers summoned by a smartphone to the user's location with the destination set. ${ }^{4}$ In this case, the car represents a network which is activated by another network, which, in turn, delegates the movement performed by the car.

The third kind of agency, which I intend to highlight in ANT vocabulary, is inscription, which is based on a script which has been previously created: laws, maps, codes, rules, and so on. Inscription is the process where a designer embeds a special way the user must interact with the designed object. From the perspective of ANT, a game can be studied as a designed object with inscriptions which have agency and do something with the player because the user invokes a network of actors and agencies when he starts playing a game, e.g., following the rules of the game world. A game designer must be aware of the network of actors which the specific game design can invoke if he wants to be able to use it in the process of inscription (Jessen \& Jessen, 2014).

Network is another term in the ANT vocabulary which has different connotations from those we commonly encounter in cyberculture studies. Callon (1991) explains that networks are more like associations with varying degrees of stability, connected to others' local actor-network nodes. Bonner (2016) argues that this is why the hyphen between actor and network is critical: it does not hold actors and networks apart; rather, it stresses the inter-relationship between the terms as defining each other in action. When the network has stabilized, it becomes a black box (Latour, 2005), the last of the ANT terms I want to highlight.

In recent years, according to Fragoso (2017), ANT has achieved considerable popularity, and it often becomes a metonymic reference to the work of Latour. However, she says, Latour himself sometimes has recognized the limitations in ANT; along with others scholars such as Law, Latour holds that ANT, contrary to what its name suggests, is more a method than a theory.

Following this thought, Latour proposed the idea of a cartography of controversies in the late 1990s as a methodological approach in ANT. Ultimately, Latour supports the importance of mapping controversies in ANT approaches and compares the researcher's role to a cartographer:

Similarly, ANT claims that we will find a much more scientific way of building the social world if we abstain from interrupting the flood of controversies. We, too, should find our firm ground: on shifting sands. Contrary to what is so often said, 
relativism is a way to float on data, not drown in them [...] Using the example of our cartographer, it is as if she had to deal not only with multiple reports coming from many travelers but also with multiple projection grids, where each point is requesting its own ad hoc coordinates. Faced with this confusion, one may decide to restrain the range of controversies or to unleash all of them. [...] The drawback is that throughout their travels readers have to support themselves on a strange diet: they have to feed off controversies about what the social is made out of (2005, pp. 24-25).

Similar to Latour's thoughts, Law (2004, p. 144) defines the concept of method assemblage as a reference to the "continuing process of crafting and enacting necessary boundaries between presence, manifest absence and otherness [...] it works by detecting and creating periodicities in the world." The ANT scholar Venturni (2010, pp. 258-259) goes even further, arguing that the "cartography of controversies is the exercise of crafting devices to observe and describe social debate especially, but not exclusively, around techno scientific issue."

Regarding the idea of controversy used in ANT, Venturini (2010) explains it straightforwardly: Controversies are situations where actors disagree - or agree - on their disagreement, to use Venturini's expression; controversies begin when actors discover that they cannot ignore each other, and controversies end when actors manage to work out a solid compromise to live together. In short, Venturini says that the task is just to look at controversies and tell what you see, doing nothing more than observing and describing. The Brazilian theorist Lemos (2013) corroborates Venturini's thought, arguing that a controversy makes the perfect situation in which to reveal agencies, mediations, the formation of intermediaries, and the relationships of forces before the constitution of black boxes.

Considering these terms, it is possible to realize some of the aspects which become visible in ANT. Here, the researcher is allowed to craft his own tools for observation, but, first of all, he has to look for controversies in the emerging phenomenon; then, he should expend the effort required to map these controversies and try to understand what they reveal; the chosen controversies will form the basis for a description using the essential concepts of mediators, intermediaries, translation, inscription, and delegation.

These terms from ANT have been used since 2005 as a resource in the field of game studies. We can highlight the work of Giddens as one of the first attempts to use ANT in game studies. Giddens (2005) proposes the use of ANT in a reflection along with agencies among non-humans, especially simulation and artificial life software, in Advanced Wars 2 for Game Boy.

After Giddens, Cypher and Richardsson use insights provided by Latour to reflect on the agencies perceived in MMORPGs. For Cypher and Richardsson (2006), MMORPGs can be considered as sociotechnical, or in Latour's terms, as multi-perspectival, generative, dynamic, embodied, and open-ended networks of human and non-human agency. MMORPGs and ANT are the issues addressed by Chen (2010) in his Ph.D. thesis, providing an analysis centered on agencies among gamers and the members of larger gaming circles 
in WoW who are engaged in a joint task called raiding. ${ }^{5}$ Following Chen's direction, other researchers have adopted ANT to develop an approach for MMORPG and its players, such as Silva and Tomimatsu (2013) and Hung (2017).

Jari Jessen and Carsten Jessen offer an interesting approach regarding games and ANT, as well. The authors demonstrate how games are actors and organizers of actors and actions based on ANT. According to Jessen and Jessen,

The main idea of ANT is that actions always take place in interaction in networks when actors influence each other in a struggle for power. We usually see social interaction between humans this way; however, ANT differs from traditional social theory by stating that the actors are not only humans but can be other elements as well (2014, p. 115).

Bienia (2016) presents what is perhaps the most complete study mixing ANT and research method for game studies, especially role-playing games. He uses concepts from ANT to analyze projects in three categories: live action role-playing games, mixed reality roleplaying games, and tabletop role-playing games. Bienia understands that ANT is a mixed method which adds to the repertoire of methods available to game studies because it focuses not solely on people but encourages attention to all the actors in the networks which constitute the games, i.e., it also requires that all the actors in the network are treated equally.

There are several interesting concepts in Bienia's work, e.g., the role of time and space as actors in the game network. For instance, the use of time in chess turns the game of chess into fast chess, and the clock becomes a mediator which modifies how the game session works. An intermediary of fast chess could be a wooden chessboard because the wood prevents the board from changing and, thus, spreads the agency of chess playing without changing it across the network of players, pieces, and so on. (p. 29). By studying live-action role-playing, or larping, Bienia came to understand that the location, as in the case of the use of Utopion ${ }^{6}$ as a playground for larpers, is a mediator which transforms the players' actions. In addition to the location, Bienia highlights the role of the garb, which could affect the gameplay of a role-playing game (RPG). The garb, he says, is different from other costumes we can use in carnival or cosplaying.

In cosplay, for example, costumes have at least two different functions. The costume represents a character, just as a costume in carnival, but a cosplay uses it for performing a character that can involve role playing, for example when being on a stage or posing for pictures. The difference to larp is the combination of actors. A cosplay costumes can use less sturdy materials [...] cosplay costumes lack the relation to ludic actors, such as armour points in larp. It is this combination or network of actors that distinguishes garb (Bienia, 2016, p. 72). 
However, Bienia displays a central misunderstanding in his work, when he says, "the main methodological principle of ANT is to 'follow the actors'" (Bienia, 2016, p. 17). On the other hand, Latour has previously said that "follow the actors" is a kind of slogan for ANT, not a methodological approach, such as the previously discussed cartography of controversies.

\footnotetext{
Using a slogan from ANT, you have "to follow the actors themselves," that is try to catch up with their often wild innovations in order to learn from them what the collective existence has become in their hands, which methods they have elaborated to make it fit together (Latour, 2005, p. 12).
}

As in other approaches used for game studies and ANT, in Bienia's work, the importance of the controversy is missing; basically, he and the other authors use terminologies from the ANT vocabulary in their descriptions and often do not consider the role of nonhumans; indeed, the controversy's role in the description as whole is strangely ignored.

To follow the actors can be a useful exercise to understand roles, such as mediators and intermediaries and, perhaps, the agencies among them; however, to look for controversies allows a full comprehension of the entire network because a controversy tends to reveal conflicts between these actors, besides just between the roles and agencies. Along with the controversy, obviously, the scholar must deal with other methodological aspects, such as the research question and the hypothesis.

In the next section, I will describe the network created by this experience with locative gaming. I will use, as the starting point for my analysis, a controversy between the gameplay of two Pokémon projects for mobile platforms: Pokémon $\mathrm{GO}$ and the classic Pokémon for Game Boy.

\section{On actors and networks: Describing the forces in Pokémon GO}

Shifting my scope to the first generation of Pokémon video game series (1996-1999) for Nintendo's Game Boy, it is possible to realize a controversy about gameplay aspects between the classic game and Pokémon GO. Ultimately, to launch a battle in Pokémon for Game Boy, the players must find each other physically and connect the devices through the Game Link cable. On the other hand, to launch a battle in Pokémon GO, the players must go to the location indexed by a Gymnasium and access it using the game app; unlike the experience in Game Boy, the player in Pokémon GO can do everything while mobile around the city. Although both games were designed for mobile devices (Game Boy and smartphone), the gameplay of Pokémon $\mathrm{GO}$ improves the physical mobility of the player, while the classic Pokémon gameplay is predominantly static.

This controversy between the two gameplays highlights that the core game mechanics in Pokémon $\mathrm{GO}$ is the result of one specific factor: walking. Game mechanics is everything which determines interactions among games and their players (Jørgensen, 2013). Using 
concepts from object-oriented programming, Sicart (2008) defines game mechanics as methods invoked by agents, designed for interaction with the game state. To perform any kind of agency available on Pokémon $\mathrm{GO}$ - to capture Pokémon, to interact with Pokéstop, to hatch an egg, to battle in Gyms, and so forth - first, the player should walk. Of course, this condition often shifts in some sense. A Pokémon could appear, e.g., when the player is stopped; sometimes, the player can join a battle in Gyms without changing position in the space; or he can check-in at a Pokéstop when he is sitting at home.

Following these core game mechanics, we can find some ways to aid the progression of players: to capture, to evolve, and to transfer Pokémon, and to fight in Gyms. Obviously, these alternatives point to other game mechanics, such as first-person shooting, in an attempt to catch a Pokémon; resource management to administer the player's inventory, to buy items on the game store, and to choose a Pokémon to battle; and other functions which enable a player to settle them in a Gym, or otherwise to send them to a NPC called Professor Willow, to switch modes, to deal with the screens alongside the game, and so on. To help in his or her progression, the player can find support in Pokéstop, spinning the tile to get game tokens (such as fruit, Pokéball, and egg) or fixing a lure module to attract Pokémon.

All interactions allowed in Pokémon $\mathrm{GO}$ can be performed only with one device, the smartphone, which becomes a mediator in the network. However, the player can simultaneously use wrist devices, such as the wristbands Pokémon Go Plus and Go-tcha for Pokémon GO, or an Apple's iWatch. The use of these devices in connection with Pokémon GO could considerably affect its gameplay because it simplifies the execution of at least three interactions: to hatch the eggs, a way to get a new Pokémon; to spin the tile available in a Pokéstop, to get game items; and to notify the player about nearby Pokémon or a nearby Pokéstop. The Go-tcha wristband goes even further: automatically, it captures nearby Pokémon and spins tiles in a nearby Pokéstop.

Here, all these wrist devices play the same role as the clock in Bienia's example; they become mediators which modify the game session, making some interactions easier and faster. It is important to highlight the role of intermediaries, such as 3G/4G wireless networks which connect the game to the Internet and the smartphone to the wristband or iWatch. Thus, the agency between both devices is a delegation because the smartphone is a mediator which makes the other actant, the wrist device, do things in the game.

The game app is also a non-human mediator, which is connected by inscription to at least two non-human actants and, consequently, to others' background networks. They become actants in the Pokémon GO network, with its own agencies which affect the gameplay.

The first actant is the game design process; its background network includes the staff from Nintendo, Google, and Niantic Lab, such as game designers, interface designers, programmers, executive producers, beta testers, and others, and non-human actants, as in the case of the game design documents, scripts, rules, and game codes, among other 
components. There is a notable agency of inscription which I must highlight concerning this network: The locations of Gyms and Pokéstops match the locations of Portals in Ingress, a locative game developed by Niantic Lab in 2012; their sites are the same because of this agency of inscription, which connects both user interfaces in the game design process.

Secondly, the other non-human actant is the urban space of Copenhagen. As an integral factor of the game design process, it consists of a background network formed by urban planners, engineers, architects, squares, streets, pedestrians, vehicles, software, and specific tools. When the player moves himself from one place to another in the city while playing Pokémon $\mathrm{GO}$, he must follow traffic conventions and cultural expectations which are inscribed in the urban space; in the same way, he must deal with other spatial factors, such as hills, flattened surfaces, and crowded places. Thus, the space becomes a mediator in the network because it modifies how the player walks in Pokémon GO.

As an actant, the Pokémon $\mathrm{GO}$ app uses its rules to let the player become aware of these agencies' allowed affordances during the game. At first glance, the game rules may seem like mere intermediaries, considering the eventual function of transporting the information from the software to the player; however, if we consider that the rules make the player do things, which relates to the game mechanics I previously described, they become a non-human mediator in the network.

To analyze the translation agencies in Pokémon GO, it is important to get back to Latour's thoughts regarding the five forces of interest; I realize the incidence of at least three of these forces of interest while playing Pokémon GO. Translation one occurs when the player freely chooses to play the game, using the app to activate the entire network connected to Pokémon GO.

Another force of interest is translation two, which happens when the player becomes stronger than the game app, shifting the focus on the network to himself or herself. One example, which reflects this situation, takes place every time a player inserts a lure module in a Pokéstop. A lure module is an in-game tool used to attract more Pokémon to a specific location; however, while it attracts more Pokémon, it consequently attracts more players, as well.

I realized this situation when I played Pokémon GO in Christianshavn, between the locations of the statue of Bishop Absalon, a monument which symbolizes the founding of Copenhagen, and the nearby fountain in Strøget, a famous pedestrian area in the city center. Respectively, there is a Gym in the statue of Absalon's location, and there is a Pokéstop settled in the fountain. The perimeter between these locations is always crowded with people interested in everyday activities, such as meeting others, watching public performances of street art, and shopping for souvenirs, designer goods, or fashions. Also, pedestrians and cyclists usually take this way to go to Christiansborg Castle, the Canal Tour boat station, or other sites. 
Sometimes, I dropped a lure module in this particular Pokéstop. This kind of translation agency can shift the focus on the network to me pesonally, e.g., considering that my nickname appeared in the Pokéstop as the lure module's owner. While attracting more Pokémon to the Pokéstop under my lure module's effect, I could attract other players as well, which meant I was connected to others' networks.

One day, a raid battle started at the Gym located in the statue of Absalon. A raid battle happens when a group of up to 20 players engages against a powerful Pokémon in a Gym. When a raid battle starts, the nearby players are notified by the user interface, serving as kind of invitation that inducts movements to the location. In this situation, the focus on the network shifts to the specific Gym itself.

Another raid battle started nearby at the IT University of Copenhagen, in a Pokéstop settled in the student's residence building. I was there to play Pokémon GO with two friends. However, it was necessary to have at least two other players to defeat the Pokémon in those battles. Suddenly, a lure module activity started in a nearby Pokéstop, and there were three teenagers involved. I walked toward them to ask if they were playing Pokémon $\mathrm{GO}$, and I invited them to join our raid battle. Here, one player had used the lure module and the Pokéstop to attract my attention to his network.

It is important to highlight that, to join a raid battle, all the players must use a specific game item which is called raid pass. This requirement indicates the force of interest translation five, proposed by Latour, in which a force becomes indispensable to reach another movement in the network; in this case, a raid pass was mandatory to join a raid battle. Another occurrence of translation five happened when I chose to use the means of transportation to play the game; it became an obligatory force in order to reach more Pokéstops in a short time.

Similar to the example of time in chess, several means of transportation could be used to improve the player speed and mobility in Pokémon GO. Basically, the alternatives available in Copenhagen are bus, car, subway, train, and bicycle. Automatically, I discarded the car considering an elementary reason: The game sends a message - Don't play Pokémon $\mathrm{GO}$ while driving - every time it detects an increase in a player's speed. Regarding the use of the subway and train, they do not allow one to access several agencies because they run very fast. The most appropriate choice would have been a bicycle, one of the most important cultural identities in Denmark; however, I chose the bus because it is the one which presents an interesting force for my analysis: the route.

A bus works as intermediary many times in everyday life because it has the function of transporting people from one place to another. However, we must consider that every bus is attached to a route which indicates its itinerary in the urban space. Without a predefined route, the bus is just another vehicle in the town. This kind of association between the bus and the route forces the player to engage in various agencies while playing Pokémon GO. 
To cross the city center, passing through locations in Nyhavn, Kongens Nytorv, and Christianshavn, I was able to use the buses 5C, 2A, or 350S. However, the 350S's route has the best itinerary, cruising near or through famous and beautiful places in Copenhagen. When this bus crosses the zone of Kongens Nytorv, there are several curves among the Pokéstops. This physical feature of Copenhagen's urban space forces the bus to slow down or, sometimes, to stop its movement, which makes the task of spinning the tiles on the top of a Pokéstop much easier. On the other hand, the $5 \mathrm{C}$ and $2 \mathrm{~A}$ routes have more stretches in a straight line, which makes it more difficult to have interactions with Pokéstops.

\section{Final thoughts}

After the description, it is important to line up agencies and mediators in this network created by locative gaming. First, a controversy between the gameplay of Pokémon GO and the classic Pokémon for Game Boy worked as foundation for my analysis. The controversy does not replace the role of a research question or a hypothesis; rather, it works as a complement to these components, establishing a starting point for the scholar's ultimate description.

As I attempt to follow the actants based on this controversy, it is possible to highlight as mediators the following: players, which are the devices used to play, as in the case of the smartphone and the watch; the game rules, which are related to the mechanics and action in Pokémon GO; the space, which modifies the intensity of walking, the core game element in Pokémon GO; the means of transportation, which increases the player's mobility in the space; the game app, which is connected to two other actants and its background networks; the urban space, in this case, which is related to the city of Copenhagen; and the game design process itself.

Delegation is the agency which links the smartphone to the wristband used to play Pokémon GO, modifying some in-game tasks, such as hatch the eggs, spin tiles in Pokéstop, and, sometimes, catch nearby Pokémon. The agency of inscription connects the game app to the urban space, to the game code developed in the game design process, and the game design to the user interface of Ingress, another locative game created by the same developer.

Translation agency in Pokémon GO connects the player, the game app, the devices, the space, and other actants using several forces of interest. Translation one occurs when the player freely chooses to play the game, using the smartphone and the app to activate the network linked to the game. Translation two happens every time the player shifts the focus of the network to himself or herself, e.g., dropping a lure module in Pokéstop. Translation five takes place every time one must call upon another force to do some task in the game, e.g., making a raid pass to access raid battles or taking a bus or others means to reach a Pokéstop. 
Finally, it is possible to conclude that ANT is compatible with game studies, particularly locative games, because it considers equally humans and non-humans; in locative gaming, the player must access more agencies beyond the game content and platform, such as the game app, the smartphone, and wristbands; also, he should interact with everyday objects, vehicles, pedestrians, and traffic rules, among other things in the urban space. In the same way, ANT becomes a productive and effective research method because it provides useful categories to support the scholar in the description regarding locative games, such as actants, mediators, intermediaries, inscription, delegation, and translation; all these labels can be used to describe the action taken by either humans or non-humans.

My choice, then, was to use Latour's concepts because they support the importance of the controversies in a description using ANT; also, Latour provides a didactic overview regarding ANT's core concepts which support an introductory approach such as this study. However, in the future, in order to develop more comprehensive approaches, scholars should consider other aspects of ANT along with the cartography of controversies, as in the case of Law's idea of method assemblage.

Also, in future works, the issue of action in games could be explored using ANT because it focuses on how people and things act and interact. In the same way, the controversy I presented here could provide more insights in forthcoming works, e.g., a research regarding the mobility factor in Pokémon GO. Likewise, this experience in locative gaming suggests a relationship between game mechanics and agencies which deserves a deep exploration in future studies.

Another future approach for locative games could consider issues on platform studies, using ANT as the main methodology. It is also important to understand the settings of the various background networks connected to Pokémon GO, as in the case of the user interface of Ingress; on the other hand, to assure the efficiency of this method in locative game research, other researchers must try to replicate it in other situations.

\section{References}

Aarseth, E. (2000). Allegories of space: The question of spatiality in computer games. In M. Eskelinen, \& R. Koskimaa (Eds.), Cybertext yearbook 2000, University of Jyväskylä. Retrieved from: http://www.hf.uib. no/hi/espen/papers/space/

Aarseth, E. (2003) Playing research: Methodological approaches to game analysis. Spilforskning Conference. Retrieved from: http://www.bendevane.com/VTA2012/herrstubbz/wpcontent/uploads/2012/01/02. GameApproaches2.pdf

Andrade, L.A. (2015). Jogos digitais, cidade e (trans)mídia: A próxima fase. Curitiba: Appris, 2015.

Andrade, L.A. (2016). Jogos locativos (Locative Games). Salvador: EdUFBA.

Benford, S., Crabtree, A., Flintham, M., et al. (2006). Can you see me now? Transactions on ComputerHuman Interaction, 13(1), 100-133. 
Bienia, R. (2016). Role playing materials. Braunschweig: Zauberfeder Verlag.

Bonner, W.B. (2016). History and IS - Broadening our view and understanding: Actor-network theory as a methodology. In L.P. Willcocks, C. Sauer, \& M.C. Lacity (Eds.), Enacting research methods in information systems (Vol. 1). London: Palgrave Macmillan, Cham.

Callon, M. (1991). Techno-economic networks and irreversibility. In J. Law, J. (Ed.), A sociology of monsters: Essays on power, technology and domination. London: Routledge.

Chen, M. (2010). Leet noobs: Expertise and collaboration in a World of Warcraft player Group as distributed sociomaterial practice. Ph.D. Thesis. University of Washington.

Colley, A., Thebaut-Spieker, J., \& Lin, A. (2017). The geography of Pokémon GO: Beneficial and problematic effects on places and movement. Retrieved from: http://www.brenthecht.com/publications/chi17_ geographyofpokemongo.pdf

Consalvo, M., \& Dutton, N. (2006). Game analysis: Developing a methodological toolkit for the qualitative study of games. Game Studies: The International Journal of Computer Game Research, 6(1). Retrieved from: (http://gamestudies.org/0601/articles/consalvo_dutton).

Cypher, M., \& Richardsson, I. (2006). An actor-network approach to games and virtual environments.

Da Silva, S.T., \& Tomimatsu, K. (2013). Game prototyping with community-driven narrative actor-network theory applied for massively multiplayer online games development. IEEE 2nd Global Conference on Consumer Electronics (GCCE). nburg: Nordicom.

Flanagan, M. (2009). Critical play: Radical game design. Cambridge/London: MIT Press.

Fragoso. S. (2017). Os modos de existência do gameplay: Um exercício de aplicação com cities: skylines. XXVI Encontro da Compós: São Paulo. Retrieved from: http://www.lume.ufrgs.br/ handle/10183/166205

Giddens, S. (2006). Walkthrough: Videogames and technocultural form. Ph.D. Thesis. University of the West of England.

Hine, C. (2000). Virtual ethnography. London: Sage Publications.

Hinske, S., Lampe, M., Magekurt, C., \& Rocker, C. (2007). Classifying pervasive games: On pervasive computing and mixed reality. Retrieved from: http://www.vs.inf.ethz.ch/publ/papers/hinske-pg07-pervasivegames.pdf

Hung, A. (2017). Beyond the player: A user-centered approach to analyzing digital games and players using actor-network theory. E-Learning and Digital Media, 13(5-6), 227-243.

Jansson, A \& Falkheimer, J. (2006). Geographies of communication. The spatial turn in media studies. Götenburg: Nordicom

Jessen, J.D., \& Jessen, C. (2014). Games as actors - Interaction, play, design, and actor-network theory. International Journal on Advances in Intelligent Systems, 7(3-4), 412-422.

Jørgensen, K. (2013). Gameworld interfaces. Boston: MIT Press.

Kalnins, K. (2003). Locative Media. Location-Based Workshop in Karosta, Latvia. Retrieved from https:// archive.org/details/agryfp-2003-locative-media-workshop-images.

Konzack, L. (2002). Computer game criticism: A method for computer games analysis. In Proceedings of Computer Games and Digital Cultures Conference. F. Mäyrä (Ed.), Tampere: Tampere University Press.

Kozinets, R. (1998). On netnography: Initial reflections on consumer research investigations of cyberculture. Advances in Consumer Research, 25, 366-371.

Lankosky; P., \& Bjork, S. (2015). Game research method: An overview. Pitsburg: ETC Press.

Latour, B. (1988). Science in action. Cambridge: MIT Press.

Latour, B. (2005). Reassembling the social: An introduction to actor-network theory. Oxford: Oxford University Press.

Law, J. (2004). After method: Mess in social science research. London/New York: Routledge. 
Law, J. (2007). Actor network theory and material semiotics. Retrieved from: http://www.heterogeneities. net/publications/Law2007ANTandMaterialSemiotics.pdf

Lefebvre, H. (1991). The production of space. London: Blackwell.

Lemos, A. (2010). Locative media and surveillance at the boundaries of informational territories. In R.

Firmino, F. Duarte, \& C. Ultramari (Eds.). ICTs for mobile and ubiquitous urban infrastructures: Surveillance, locative media and global networks. Hershey: IGI Global.

Lemos, A. (2013) A comunicação das coisas: teoria ator-rede e cibercultura. São Paulo: Annablume.

Licoppe, C. (2017). From Mogi to Pokemon Go: Continuities and change in location aware - collection games. Mobile Media \& Communication, 5(1), 24-29.

Luksac-Roesche, M. (2017). Towards an understanding of the effects of augmented reality games in disaster management. Retrieved from: https://arxiv.org/abs/1702.06610

McGonigal, J. (2007). The Puppet Master Problem: Design for Real-World, Mission-Based Gaming. In Harrigan, P. \& Wardrip-Fruin. Second Person: role-playing and story in games and playable media. Cambridge: MIT Press.

Montola, M., Stenros, J., \& Waern, A. (2009). Pervasive games: Theory and design. Oxford: Morgan Kaufmann

Sicart, M. (2008). Defining game mechanics. Game Studies: The International Journal of Computer Game Research, 8(2). Retrieved from: http://gamestudies.org/0802/articles/sicart

Soja, E. (1989). Postmodern geographies: The reassertion of space in critical social theory.London/NewYork: Verso.

Szulborski, D. (2005). This Is Not a Game: A guide to alternate reality gaming. Santa Barbara: eXe Active Media Group.

Tan, C., \& Soh, D. (2010). Augmented reality games: A review. Retrieved from: http://chek.gamesstudio.org/ wpcontent/uploads/2011/02/TanAndSoh_GAMEON.pdf

Venturini, T. (2010). Diving in magma: How to explore controversies with actor-network theory. Public Understanding of Science, 19(3), 258-273. Retrieved from: http://pus.sagepub.com/content/19/3/258

Wong, F. (2017). Influence of Pokémon Go on physical activity levels of university players: A cross-sectional study. International Journal of Health Geographics, 16(8). Retrieved from: https://www.ncbi.nlm.nih. gov/pmc/articles/PMC5322678/

\section{Endnotes}

1 https://www.forbes.com/sites/insertcoin/2017/04/05/believe-it-or-not-pokemon-go-has-65-millionmonthly-active-players/\#9c107c8121d7. Accessed: July 2017.

2 In narrative theory, actant is a term from the actantial model of semiotic analysis of narratives and it also has use in linguistics, sociology, computer programming theory, astrology, and so on. (cf. Latour, 2005).

3 https://waymo.com/journey/. Accessed: July 2017.

4 https://www.theguardian.com/technology/2014/may/28/google-self-driving-car-how-does-it-work. Accessed: July 2017.

5 According to Chen (2010, p.13), "these raids normally take place for several hours at a time, often repeated across several weeks or months, before the team is able to accomplish the final goal of defeating every monster within the raid zone."

6 Utopion is a location in Bexbach, Germany, which people often use for larping. http://larpgelaende.de/ Accessed: May 2018. 
Article: Research method for locative games

Luiz Adolfo Andrade

Adjunct Professor

Department for Human Sciences - III

State University of Bahia, Brazil

Visiting Scholar

Center for Computer Games Research (2017-2018)

This work was supported by CAPES Postdoctoral Stage Scholarship, process number 88881.119487/2016-01. 